\title{
EDITORIAL
}

\section{Preface for Frontiers in Management and Business}

\author{
Editor-in-Chief: Hideaki Sakawa
}

Welcome to our new Journal on the science of business and management! Frontiers in Management and Business $(F M B)$ is an international journal for global scholars and practitioners to provide original researches and insights in the field.

$F M B$ seeks to provide an important venue for the discussion of management and business issues from perspectives of accounting, finance, and management. Previous studies in these areas are mainly focused on Western countries, especially United States. This can lead a lack of evidences or theoretical developments in other economies. In most fields related to management $\&$ business, theories have been developed based on the Western developed economies of the world. We may be tempted into thinking whether these theories are applied to and modified to other economics.

The aim of the Journal is to reveal the management and business difference of each nation and region that have different systems. In management and business area, many theoretical perspectives have been developed. For instance, crosscountries differences of social, economic, and political factors give diverse pressures especially in the Multi National Entities (MNEs) under the institutional frameworks. From the perspective of resource-based-views, strategy of firms might have heterogeneous because they have different resources to gain a competitive advantage in each

Received: Feb. 11, 2020; Accepted: Feb. 12, 2020; Published: Feb. 13, 2020

Correspondence to: Hideaki Sakawa, Graduate School of Economics, Nagoya City University, Nagoya, Japan; Email: sakawa@econ.nagoya-cu.ac.jp

Citation: Sakawa H. Preface for Frontiers in Management and Business. Front Manage Bus, 2020, 1(1): 1.

Copyright: (c) 2020 Hideaki Sakawa. This is an open access article distributed under the terms of the Creative Commons Attribution License, which permits unrestricted use, distribution, and reproduction in any medium, provided the original author and source are credited. industry or market. Agency theory applies to reveal the difference of monitoring mechanisms between dispersed and concentrated ownership structure countries like Anglo Saxon countries. Related to agency theory, corporate governance is on the way of reforming all over the world, especially in Asian countries. Thus, papers related to corporate governance might be valuable topics for policy-makers and practitioners. Unfortunately, most previous studies tend to focus to analyze western countries. In fact, there remains lack of evidences about family firms which are widely observed family firms in non-Anglo Saxon countries. These are several examples of important topics for FMB and our topics are not restricted to the above points. We think about every management and business phenomenon to apply theoretical explanations.

\section{About “Call for Papers” of Launch Issue}

I am delighted to announce the "call for paper" of our launch issue. We open with any topics related to Management and Business areas. FMB is also open to different methodological approaches, including, quantitative, qualitative, mixed methods, theoretical study, and case work, contributing to an understanding of something new in Management and Business. In addition, perspective and review papers are also welcome to submit. We are very much welcome to submit your high quality manuscripts in FMB in the future. 